\title{
Mechanism of Multi-loop Edgewise Archwire technique in correcting anterior open bites of Class II malocclusion patients with temporomandibular disorders - cephalometric assessment
}

\section{Huanye Liu}

School and hospital of stomatology, China Medical University

\section{Heeyeon Suh}

University of the Pacific - Arthur A Dugoni School of Dentistry

\section{Young-Eun Jung}

University of the Pacific - Arthur A Dugoni School of Dentistry

Kaiyuan Xu

University of the Pacific - Arthur A Dugoni School of Dentistry

\section{Dan Zhang}

School and hospital of stomology, China Medical University

Heesoo Oh ( $\nabla$ hoh@pacific.edu )

University of Pacific https://orcid.org/0000-0002-6029-6064

\section{Research article}

Keywords: MEAW (Multi-loop Edgewise Archwire), Open bite, TMD (temporomandibular disorders), Stabilization splint, Orthodontics

Posted Date: June 3rd, 2020

DOI: https://doi.org/10.21203/rs.3.rs-31981/v1

License: (c) (7) This work is licensed under a Creative Commons Attribution 4.0 International License. Read Full License 


\section{Abstract}

Background: An anterior open bite is considered challenging to treat because of its multifactorial etiology. Condylar resorption, which is one of the temporomandibular disorders (TMD) symptoms, has been identified as an etiologic factor of anterior open bites. It is essential to find an effective and efficient method to correct open bites while reducing the risk of exacerbating TMD during orthodontic treatment.

Objectives: To evaluate the effect of the multi-loop edgewise archwire (MEAW) technique in correcting anterior open bite in patients with TMD.

Materials and Methods: In this retrospective study, 20 patients with anterior open bites and TMD were included. 19 cephalometric measurements and 2 open bite indices were evaluated. A paired t-test was used to assess changes between pre- and post-treatments.

Results: There were statistically significant changes after the treatment using the MEAW technique. The cephalometric measurements, including vertical positions of the incisors and molars, changed significantly. The maxillary and mandibular regional superimpositions for a subgroup of non-extraction patients showed slight intrusion of the upper molars $(-0.6 \pm 1.0 \mathrm{~mm}, \mathrm{p}=0.04)$ and slight extrusion of the lower molars $(1.0 \pm 1.1 \mathrm{~mm}, p<0.01)$. Open bite correction was achieved predominantly through retraction and extrusion of the upper and lower incisors.

Conclusions: The anterior open bite was successfully corrected by using the MEAW technique. However, the primary mechanism was the extrusion of the anterior teeth with a maintained vertical dimension. In the absence of apparent symptoms of joint discomfort, it is effective and relatively safe to use the MEAW technique to treat open bite patients with TMD.

\section{Background}

Whether patients with the temporomandibular joint disorder should receive orthodontic treatment has been a controversial topic in dentistry. At present, the role of orthodontic treatment in the etiology of TMD has not been confirmed [1, 2]. Based on the previous studies, orthodontic treatment should not be initiated on a patient who presents with orofacial pain [1, 2]. The signs and symptoms of TMD are unpredictable and can appear at various stages of orthodontic treatment. If a patient develops symptoms during orthodontic treatment, the first consideration should be to stop active orthodontic treatment and make a diagnosis based on current symptoms. When the patient's pain disappears or subsides, orthodontic treatment can be continued as planned or be adjusted according to the patient's condition. Orthodontic treatment does not increase a patient's risk for TMD, nor does it worsen previous symptoms.In contrast, according to the literature, patients with Class II malocclusions and muscle-derived TMD appear to benefit functionally from orthodontic treatment [3]. However, patients with TMD also seem to be less adaptive to occlusal changes and are highly susceptible to occlusal instability $[4,5]$.

The open bite malocclusion is considered difficult to treat because of its multifactorial etiology. Mandibular condylar resorption, which is one of the TMD symptoms, has been identified as an etiologic factor of anterior open bites [6]. It has been suggested that orthognathic surgery, such as maxillary impaction with autorotation of the mandible, can provide an ideal treatment outcome in a non-growing patient with a severe skeletal open bite [7].However, patients with preexisting signs and symptoms of TMD are likely to have a significant worsening of their TMJ dysfunction after surgery, particularly after mandibular advancement or counterclockwise rotation. This is especially true in patients with displaced articular discs; if the discs remain displaced after surgery, the condyle 
can compress the bilaminar tissue against the superior and posterior walls of the fossa. This compression can contribute to pain and inflammation and initiate condylar resorption [8]. Class II patients with high occlusal plane angles and articular disc displacement may have less satisfactory outcome than patients with normal- or lowangle mandibular retrognathism or prognathism [9].Because of this unpredictability, surgery might not be a viable option for a patient who has a severe skeletal open bite due to degenerative condylar resorption as there is a high likelihood of further condylar resorption. Therefore, the treatment of anterior openbite with Class II malocclusions associated with degenerative condylar resorption is considered a clinical challenge.

Among the various treatment modalities that have been proposed, the multi-loop edgewise archwire (MEAW) technique appears to be an effective and efficient method to correct anterior open bites. In 1987, Kim [10] introduced the MEAW technique and reported that clockwise rotation of the maxillary occlusal plane and counterclockwise rotation of the mandibular occlusal plane contribute to the closure of the open bite [11]. Fushima et al.[12] suggested that the MEAW technique can be effectively and efficiently used to correct open bites and reduce the risk of exacerbating TMD during orthodontic treatment, even resolving TMD symptoms in some patients with open bites and TMD. However, there have been no studies that evaluated the effectiveness of the MEAW technique in treating open bite patients with TMD.

This retrospective study aimed to investigate how the MEAW technique corrects the anterior open bites in Class II malocclusion patients with TMD. This paper attempts to answer the following questions:

- How much open bite correction can be achieved using the MEAW technique?

- How much molar intrusion and incisor extrusion occur using the MEAW technique?

- How often does open bite correction using the MEAW technique affect TMD symptoms?

\section{Materials And Methods}

The sample was collected from orthodontic patient archives between 2014 and 2018 at the Department of Orthodontics, School of Stomatology, China Medical University. The primary inclusion criteria were patients who: 1) presented with an anterior open bite (overbite less than $0 \mathrm{~mm}$ ); 2) presented with Class II molar relationship and $\mathrm{ANB}>3^{\circ} ; 3$ ) were over the age of 15 and were treated with fixed appliance therapy using the MEAW technique; Exclusion criteria included patients who had: 1) previous orthodontic treatment; 2) craniofacial anomalies; 3) orthognathic surgery. Twenty patients (4 males and 16 females) were included in the sample (Table 1). The study was approved by the institutional review board of the School of Stomatology, China Medical University (k202002).

\section{TMD evaluation and management}

After a comprehensive evaluation of the diagnostic records for skeletal pattern, dentoalveolar condition, and facial esthetics, a detailed treatment plan was proposed. Clinical evaluation of the TMD symptoms and signs were recorded before, during, and after treatment. Four patients presented with a history of TMD, but no current symptoms. 16 patients presented with TMD related symptoms (such as deflection upon opening, the clicking of the joint, limited opening, etc.).. TMJ images (MRI or CBCT) were obtained for 16 symptomatic patients. Conservative treatments, including medication, physiotherapy, occlusal splints, and self-management strategies, were utilized to relieve the symptoms. 9 out of 20 patients received a stabilization splint for three to six months to resolve TMD symptoms prior to orthodontic treatment (Table 2). All, except two, patients presented with no TMD 
symptoms before orthodontic treatment. The two patients with remaining symptoms initially presented with severe open bites and TMJ pain. The pain was alleviated significantly, but their TMD symptoms were not completely resolved. The TMD symptoms were monitored throughout orthodontic treatment, and the symptoms did not get worse. Mild discomforts remained after orthodontic treatment. The TMD status at T1 and T2 was shown in Table 1.

\section{Treatment modality}

According to the treatment plan, the majority of patients needed extraction of permanent teeth, including the 3rd molars, to relieve anterior and/or posterior crowding (Table 1). All patients were treated with an 0.018 "-slot standard edgewise appliance system. After leveling and aligning and space closing, 16X22SS MEAWs, comprised of $10 \mathrm{~L}$-shaped loops between the teeth, were placed in each dental arch. After each loop was activated, the maxillary archwire had an accentuated Curve of Spee and the mandibular archwire had a reverse Curve of Spee (Figure 1). Progressive tip back was incorporated into the archwire. With anterior vertical elastics, activated MEAW uprighted molars distally and intruded the molars while controlling incisor extrusion. The posterior component of force may reduce TMJ loading, create proper joint space, and establish stable occlusion. Anterior vertical elastics, or short Class II and Class III elastics, allowed the tip back activations to be expressed. Patients were instructed to wear anterior vertical elastics $(3 / 16 ", 6 \mathrm{oz})$ and-or short Class II or Class III elastics full time. The above treatment was continued until a positive overbite was obtained, which usually took about 6-12 months.

\section{Lateral Cephalometric Analysis and Superimposition}

Lateral cephalometric landmarks were digitized independently by three calibrated judges in Dolphin imaging (version 11.8; Dolphin Imaging, Chatsworth, Calif). The reliability was assessed by Cronbach's alpha, a universal ICC measure. Inter-rater reliability was excellent with an ICC greater than 0.9 for all measurements ranging from 0.932-0.997.

Twenty-one cephalometric measurements were generated by computer operations in Dolphin imaging. The average values of the three judges' estimates were used. Overbite Depth Indicator (ODI) determines the vertical maxillo-mandibular relationship. ODI is the arithmetic sum of A-B plane to the mandibular plane angle and Palatal plane to Frankfort horizontal plane angle. The Antero-posterior Dysplasia Indicator (APDI) is the arithmetic sum of three angles: Frankfort Horizontal plane to Facial plane, A-B plane to Facial plane, and A-B plane to Frankfort plane. APDI determines the horizontal maxillo-mandibular relationship as Class I, II, and III (Figure 2-A).

Two orthodontic faculty members performed superimpositions. Anterior cranial base superimpositions using the anterior wall of sella turcica, the cribriform plate, and the greater wing of the sphenoid bone were performed. To evaluate sagittal and vertical changes of the molars and incisors in non-extraction group, each patient's pretreatment ( $\mathrm{T} 1$ ) and post-treatment (T2) cephalometric tracings were superimposed using Bjork's natural maxillary and mandibular reference structures. An $\mathrm{x} / \mathrm{y}$ coordinate system was established. The palatal plane (ANS-PNS) and mandibular plane (Go-Me) at T1 became the $\mathrm{x}$-axis, while the $\mathrm{y}$-axis was the line perpendicular to the $\mathrm{x}$-axis. In terms of tooth position, a positive sign denoted superior and mesial movement, and a negative sign denoted inferior and distal movement. For instance, positive vertical movement indicates intrusion of the upper molar (U6) and extrusion of the lower molar (L6) (Figure 2-B, C). 


\section{Statistical Analysis}

Descriptive statistics were generated to report the mean, standard deviation, and range of the demographic information. A paired t-test was used to evaluate the changes between T1 and T2. P-values less than 0.05 were considered statistically significant. Statistical values were computed using SPSS for Windows version 21 and the language R (http://www.r-project.org/).

\section{Results}

The patients' mean age at T1 was $17.90 \pm 4.12$ years and at $T 2$ was $20.45 \pm 3.73$ years. The average treatment time was 2.63 years, ranging from 17 to 43 months. Table 2 shows the cephalometric measurements at T1, T2, and T2$\mathrm{T} 1$ for 20 cases. The patients presented with Class II malocclusions with retrognathic mandibles. The means of the ANB and mandibular plane angle (MP-SN) were $6.14 \pm 2.1^{\circ}$ and $42.8 \pm 8.39^{\circ}$, respectively, which indicates a Class II hyperdivergent facial type. The mean overbite was $-2.05 \pm 2.07 \mathrm{~mm}$ at T1. Table 1 shows the distribution of open bite severity at T1. At T2, there was no significant change in the skeletal anterior-posterior jaw relationship. The anterior open bite was successfully corrected and positive overbite was achieved for all patients. The mean change in overbite was $3.00 \pm 2.44 \mathrm{~mm}(p<0.001)$. 
Table 1

Patient characteristics, extraction pattern, TMD symptoms, and usage of splint before orthodontic treatment.

\begin{tabular}{|c|c|c|c|c|c|c|c|}
\hline & & & & TMD & Symptoms & (YES/NO) & \\
\hline Case & Sex & $\begin{array}{l}\text { Overbite } \\
(\mathrm{mm})\end{array}$ & Teeth extracted & $\begin{array}{l}\text { First } \\
\text { visit }\end{array}$ & $\begin{array}{l}\text { Pre } \\
\text { treatment }\end{array}$ & $\begin{array}{l}\text { Post } \\
\text { treatment }\end{array}$ & $\begin{array}{l}\text { Splint } \\
\text { (YES/NO) }\end{array}$ \\
\hline 1 & $\mathrm{~F}$ & -6.3 & LR8, LL8 & Y & $\mathrm{N}$ & $\mathrm{N}$ & $\mathrm{Y}$ \\
\hline 2 & $\mathrm{~F}$ & -0.4 & LR8, LL8 & Y & $\mathrm{N}$ & $\mathrm{N}$ & $\mathrm{Y}$ \\
\hline 3 & $\mathrm{M}$ & -2.8 & UR3, UL3, LL8, LR6 & $\mathrm{N}$ & $\mathrm{N}$ & $\mathrm{N}$ & $\mathrm{N}$ \\
\hline 4 & $\mathrm{~F}$ & -1.0 & UR8, UL8, LR8 & $\mathrm{N}$ & $\mathrm{N}$ & $\mathrm{N}$ & $\mathrm{N}$ \\
\hline 5 & $\mathrm{~F}$ & -2.7 & UR8, UL8, LR8, LL8 & Y & $\mathrm{N}$ & $\mathrm{N}$ & Y \\
\hline 6 & $\mathrm{~F}$ & -4.9 & UR8, UL8, LR8, LL8 & Y & $\mathrm{N}$ & $\mathrm{N}$ & $\mathrm{N}$ \\
\hline 7 & $\mathrm{~F}$ & -1.2 & UR8, UL8, LR8, LL8 & Y & $\mathrm{Y}+$ & $Y \dagger$ & $\mathrm{N}$ \\
\hline 8 & $\mathrm{~F}$ & -0.2 & UR7, UL7, LR8, LL8 & $Y$ & $\mathrm{~N}$ & $\mathrm{~N}$ & $\mathrm{~N}$ \\
\hline 9 & $\mathrm{M}$ & -2.6 & UR8, UL8, LR8, LL8 & Y & $\mathrm{N}$ & $\mathrm{N}$ & $Y$ \\
\hline 10 & $\mathrm{~F}$ & -0.5 & UR8 & $\mathrm{Y}$ & $\mathrm{N}$ & $\mathrm{N}$ & $Y$ \\
\hline 11 & $\mathrm{~F}$ & -0.6 & UR8, UL8, LR8, LL8 & $Y$ & $\mathrm{Y}+$ & $\mathrm{Y}+$ & Y \\
\hline 12 & $\mathrm{~F}$ & -3.1 & UR4, UL4, LR4, LL4, LR8, LL8 & $\mathrm{N}$ & $\mathrm{N}$ & $\mathrm{N}$ & $\mathrm{N}$ \\
\hline 13 & $\mathrm{M}$ & -0.9 & None & $\mathrm{Y}$ & $\mathrm{N}$ & $\mathrm{N}$ & $\mathrm{Y}$ \\
\hline 14 & $\mathrm{~F}$ & -1.0 & UR8, UL8, LR8, LL8 & Y & $\mathrm{N}$ & $\mathrm{N}$ & Y \\
\hline 15 & $\mathrm{~F}$ & -5.6 & UR4, UL4, LR4, LL4 & $\mathrm{N}$ & $\mathrm{N}$ & $\mathrm{N}$ & $\mathrm{N}$ \\
\hline 16 & $\mathrm{M}$ & -4.2 & UR8, UL8, LR8, LL8 & Y & $\mathrm{N}$ & $\mathrm{N}$ & $\mathrm{Y}$ \\
\hline 17 & $\mathrm{~F}$ & -3.6 & $\begin{array}{l}\text { UR4, UL4, LR4, LL4, UR8, UL8, } \\
\text { LR8, LL8 }\end{array}$ & Y & $\mathrm{N}$ & $\mathrm{N}$ & $\mathrm{N}$ \\
\hline 18 & $\mathrm{~F}$ & -0.1 & UL8, LR8 & $\mathrm{Y}$ & $\mathrm{N}$ & $\mathrm{N}$ & $\mathrm{N}$ \\
\hline 19 & $\mathrm{~F}$ & -0.9 & UR4, UL4, LR6, LL8 & $\mathrm{Y}$ & $\mathrm{N}$ & $\mathrm{N}$ & $\mathrm{N}$ \\
\hline 20 & $\mathrm{~F}$ & -1.6 & LR8, LL8 & $Y$ & $\mathrm{~N}$ & $\mathrm{~N}$ & $\mathrm{~N}$ \\
\hline
\end{tabular}


Table 2

Age and cephalometric measurements at T1 and T2 $(n=20)$

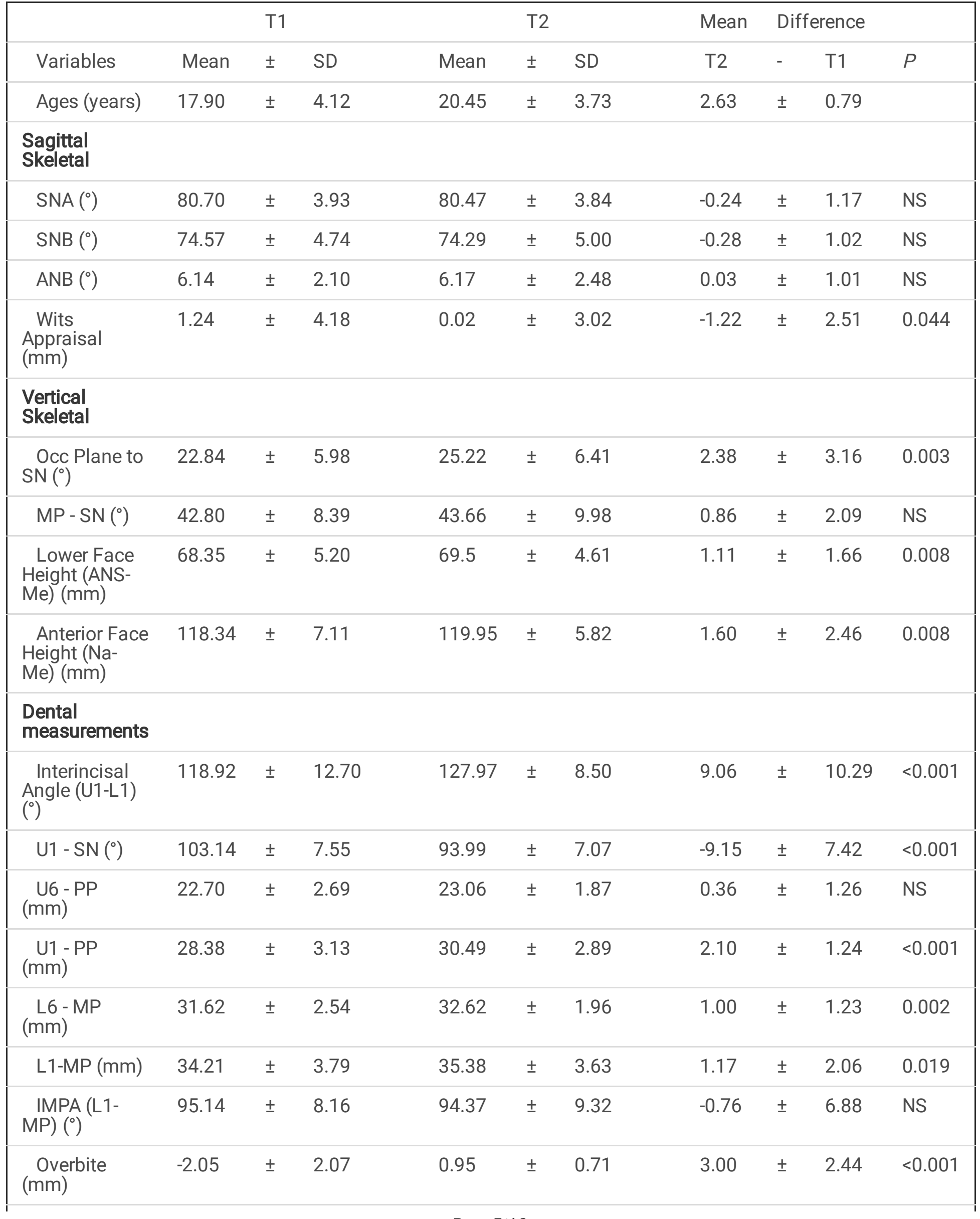




\begin{tabular}{|c|c|c|c|c|c|c|c|c|c|c|}
\hline Overjet (mm) & 5.32 & \pm & 2.37 & 2.94 & \pm & 0.69 & -2.38 & \pm & 2.48 & $<0.001$ \\
\hline \multicolumn{11}{|l|}{$\begin{array}{l}\text { Soft tissue } \\
\text { measurements }\end{array}$} \\
\hline $\begin{array}{r}\text { Upper Lip to } \\
\text { E-Plane (mm) }\end{array}$ & 1.57 & \pm & 3.02 & 1.11 & \pm & 2.60 & -0.46 & \pm & 1.60 & NS \\
\hline $\begin{array}{l}\text { Lower Lip to } \\
\text { E-Plane }(\mathrm{mm})\end{array}$ & 3.70 & \pm & 3.58 & 3.33 & \pm & 3.37 & -0.37 & \pm & 1.65 & NS \\
\hline \multicolumn{11}{|l|}{ Openbite index } \\
\hline $\begin{array}{l}\text { Overbite } \\
\text { Depth } \\
\text { Indicator (ODI) }\end{array}$ & 73.30 & \pm & 6.16 & 73.35 & \pm & 7.19 & 0.05 & \pm & 2.44 & NS \\
\hline ODI+APDI & 149.89 & \pm & 8.72 & 149.62 & \pm & 10.42 & -0.29 & \pm & 2.29 & NS \\
\hline
\end{tabular}

There were no statistically significant differences found in the vertical linear measurement of the upper molar, which indicates reasonable vertical control during treatment. However, the lower molars were extruded about $1.00 \pm 1.23 \mathrm{~mm}(p=0.002)$, which contributed to an increased occlusion plane (Occ Plane to $S N)$ and lower face height (ANS-Me). Significant extrusion was found in both the upper and lower incisors: the mean changes of U1 to PP and L1 to MP were $2.10 \pm 1.24 \mathrm{~mm}(p<0.001)$ and $1.17 \pm 2.06 \mathrm{~mm}(p=0.019)$, respectively. In addition, the measurement of upper inclination (U1-SN) was significantly reduced by about $9.15 \pm 7.42^{\circ}$, but inclination of the lower incisor was relatively maintained. These changes demonstrate typical tooth movement in Class II correction mechanics. The result also indicates that the treatment did not cause the change of relative position of the maxilla and mandible bones, the main mechanism of open bite correction was through the extrusion of the upper and lower incisors.

In order to accurately measure the sagittal and vertical movements of the incisors and molars using the MEAW technique, we performed cephalometric regional superimpositions of the maxilla and mandible to evaluate tooth movement between T1 and T2 for a subgroup of 14 non-growing patients treated with a non-extraction approach, except for 3rd molar extractions (Table 3 and Figure 2). Maxillary cephalometric superimpositions (Fig3-A and B) showed statistically significant upper maxillary molar distalization $(0.91 \mathrm{~mm})$ and intrusion $(0.61 \mathrm{~mm})$, as well as significant extrusion of the maxillary incisors $(1.84 \mathrm{~mm})$. Mandibular cephalometric superimpositions (Fig3-D) showed statistically significant lower mandibular molar extrusion $(1.01 \mathrm{~mm}$ ) on the mesial cusp and minimum (not statistically significant) intrusion on the distal cusp. This movement was caused by the uprighting of the lower first molar. Besides, the lower incisors were extruded and retroclined $(0.86 \mathrm{~mm})$. These results show that MEAW tipped the molars distally in both the upper and lower dentition. In the upper arch, slightly less than $1 \mathrm{~mm}$ of distalization was achieved by distal tipping of the molars without TADs (Temporary Anchorage Devices). 
Table 3

Incisor and molar movement on the maxillary and mandibular structural superimpositions for 14 non-extraction cases.

\begin{tabular}{|lllllll|}
\hline & \multicolumn{2}{c}{ X } & & & Y & \\
\hline & Mean & SD & $P$ & Mean & SD & $P$ \\
\hline Maxillary superimposition & & & & & & \\
\hline U1 Tip & -2.74 & 2.11 & $<0.001$ & -1.84 & 1.10 & 0.001 \\
\hline U1 Root & -0.28 & 1.30 & NS & -1.01 & 1.01 & 0.002 \\
\hline U6 Occlusal & -1.00 & 1.23 & 0.009 & 0.64 & 1.03 & 0.037 \\
\hline Mesial U6 & -0.96 & 1.15 & 0.008 & 0.61 & 1.02 & 0.043 \\
\hline Distal U6 & -0.91 & 1.06 & 0.006 & 0.81 & 1.33 & 0.043 \\
\hline Mandibular superimposition & & & & & & \\
\hline L1 Tip & 0.86 & 1.66 & 0.042 & 0.71 & 1.77 & NS \\
\hline L1 Root & 0.29 & 1.22 & NS & 0.90 & 1.16 & 0.012 \\
\hline L6 Occlusal & -0.16 & 0.97 & NS & 1.00 & 1.11 & 0.005 \\
\hline Mesial L6 & 0.05 & 0.89 & NS & 1.01 & 1.12 & NS \\
\hline Distal L6 & -0.27 & 1.10 & NS & -0.08 & 0.74 & NS \\
\hline
\end{tabular}

\section{Discussion}

The present study aimed to evaluate the treatment changes by the MEAW technique in treating anterior open bite patients with TMD. All patients, except two patients, did not present TMD symptoms throughout treatment. The two patients presented mild discomfort and did not get worse. Therefore, it appears that the MEAW technique might be a viable treatment option for patients who are not able to choose surgery as a treatment of choice. The MEAW treatment approach might help unload the joint and reduce the risk of relapse of TMD symptoms during orthodontic treatment.

The temporomandibular disorder (TMD) is defined as a set of functional and pathological conditions affecting the temporomandibular joint (TMJ), masticatory muscles and tissue, and their adjacent components [13].The relationship between occlusal factors, orthodontics, and TMD remains controversial. Based on the previous literature, orthodontics in the normal population "neither produces nor cures" the TMD [14].In clinical practice, the most common chief complaints are pain, articular sounds (clicking and creaking), limited mouth opening, and disrupted jaw movements [15]. Among the symptoms, pain is the most urgent problem that plagues patients' daily lives and is often the main reason they seek help [16]. Michelott [17] suggests that orthodontic treatment should be avoided until the pain is relieved.

It is necessary to conduct X-ray screening for patients with TMD symptoms before initiating orthodontic treatment. This will help the orthodontist determine whether the patient is in the quiescent or progressive stage, so as to avoid problems in the subsequent orthodontic treatment. Orthodontic treatment, to improve the masticatory function and 
aesthetic, can be considered once the TMD is stabilized [18, 19].At present, most experts recommend conservative treatment for mild to moderate TMD patients to stabilize the TMD. Conservative treatment usually results in satisfactory clinical outcomes. Most importantly, patients are more receptive of a more conservative approach [20, $21,22]$. Occlusal stabilization splints have always been the main treatment method for jaw dysfunction and the most common treatment method in oral instruments [23]. Occlusal splints aim to "unload" the condyles to relieve discomfort and muscular pain. Splints may help prevent the progression of TMD and can be beneficial for reducing pain [24].It is generally recognized that splints are useful in the conservative treatment of TMD [25, 26]. Once the TMD symptoms are alleviated through splint therapy, the possibility of recurrence or exacerbation of TMD symptoms by orthodontic treatment is very low. Orthodontic treatment combined with the use of a splint is effective for reducing pain and restricting mandibular movement, but not for joint sound [27, 28].

Anterior open bite is considered one of the most challenging dentofacial deformities to treat [29]. Extrusion of the upper and lower incisors is a common way of correcting the anterior open bite, which can be achieved through vertical elastics, extrusion arches [30], or a MEAW appliance [7].

The present study shows that the MEAW technique can be a viable and effective option in correcting severe skeletal open bites in patients with TMD without utilizing TADs or other auxiliaries. However, the biggest drawback of this technique is that it relies on the patient's cooperation. With poor cooperation, there are serious consequences. Moreover, it is not easy to achieve counterclockwise rotation of the occlusal plane because of the extrusion of the anterior teeth rather than the intrusion of the molars. At the same time, extruded anterior teeth are unstable and prone to relapse [31].

It has been well documented that molar intrusion is necessary for the mandible to be rotated counterclockwise, as well as to reduce the lower face height and facial convexity. In this study, from the maxillary superimposition of the non-extraction group (Table 3, Figure 3), the upper molars were intruded by $0.81 \mathrm{~mm}$ and distalized about $0.9 \mathrm{~mm}$, which is challenging to achieve without using TADs. In non-extraction group, distal tipping more than $10^{\circ}$ provided space for resolving the crowding and retracting the upper incisors as well (Table 3, Figure 3). Unfortunately, the uprighting of the mandibular molars caused extrusion of the mesial cusp by about $1.0 \mathrm{~mm}$ (Table 3, Figure 3). It seems that the MEAWs are not sufficiently effective in controlling the mandibular molars; an additional modality to control lower molars is required.

In recent years, it has become popular to use temporary anchorage devices (TAD) to correct anterior open bites [32]. Several case reports have illustrated the successful use of TADs in non-growing skeletal open bite cases that obtain "orthognathic surgery-like" results. TADs have elevated open bite correction in non-growing patients and have created higher levels of success [33].

Current evidence suggests that using the MEAW appliance in conjunction with TADs allows the lower molars to be intruded effectively with mild extrusion of the incisors. They also documented counterclockwise rotation of the mandible, which closed the anterior open bite and reduced the lower facial height to improve facial esthetics [31]. In further studies, we need to compare the long-term stability of open bite correction using the MEAW technique only and using the MEAW technique in tandem with TADs or other appliances.

Due to the nature of retrospective studies, the present study has limitations. Severe skeletal open bite with TMD is relatively rare condition, so the sample size was not ideal. TMD evaluation was based on clinical examination and 
not all patients had MRI or 3D imaging. In addition, the sample was derived from a single institution. Therefore, the generalization of the results of this study should be limited and carefully interpreted.

\section{Conclusions}

Using the MEAW technique, the maxillary molars can be intruded and distallized relatively well, but the mandibular molars need to be better controlled since there was slight extrusion from the uprighting of the molars. We can anticipate more satisfying treatment outcome by combining methods to achieve counterclockwise rotation of the mandible and improve facial aesthetics. The following conclusions can be drawn:

1. The MEAW technique can be an effective method in correcting anterior open bites in TMD patients.

2. The open bite was corrected mainly by retraction and extrusion of the anterior teeth. The vertical dimension was well-maintained for the upper molars, but the mandibular molars were extruded.

3. During treatment, the patients who had TMD did not show evident recurrence or worsening of their TMD conditions, indicating that orthodontic treatment can be performed when orthodontic treatment is required.

\section{Abbreviations}

MEAW: multi-loop edgewise archwire; TAD: temporary anchorage devices; TMD: temporomandibular disorder; TMJ: temporomandibular joint; ODI: Overbite Depth Indicator; APDI: The Antero-posterior Dysplasia Indicator; MRI: Magnetic resonance imaging; CBCT: Cone beam computed tomography.

\section{Declarations}

\section{Ethics approval and consent to participate}

This study was approved by the Medical Ethics Committee of School and Hospital of Stomatology to China Medical University (k202002), and all patients and their parents signed informed consents.

\section{Consent for publication}

Not applicable.

\section{Availability of data and materials}

The datasets used and analyzed during the current study are available from the corresponding author on reasonable request.

\section{Competing interests}

The authors declare that they have no competing interests.

\section{Funding}




\section{Authors' contributions}

LHY conceptualized and interpreted the manuscript and collected the data. SHY collected and analyzed the data, provided revision and editorial suggestion. JYE and ZD collected the data. XKY provided revision and editorial suggestion. OHS provide helpful insights and editorial suggestion.

\section{Acknowledgments}

The authors would like to express their gratitude to Dr. Sadao Sato, from the Kanagawa Dental College in Yokosuka, Japan, and Ying Bu, Peking University, School of Stomatology.

\section{References}

1. Macfarlane TV, Kenealy P, Kingdon HA, Mohlin BO, Pilley JR, Richmond S, et al. Twenty-year cohort study of health gain from orthodontic treatment: temporomandibular disorders. Am J Orthod Dentofacial Orthop. 2009;135:692.e1-8. https://doi.org/10.1016/j.ajodo.2008.10.017.

2. Gauer RL, Semidey MJ. Diagnosis and treatment of temporomandibular disorders. Am Fam Physician. 2015;91:378-86. http://www.aafp.org/afp/2015/0315/p378-s1.

3. Henrikson T, Nilner M. Temporomandibular disorders and the need for stomatognathic treatment in orthodontically treated and untreated girls. Eur J Orthod. 2000;22:283-92. https://doi.org/10.1093/ejo/22.3.283.

4. Cairns BE. Pathophysiology of TMD pain-basic mechanisms and their implications for pharmacotherapy. J Oral Rehabil. 2010;37:391-410. https://doi.org/10.1111/j.1365-2842.2010.02074.x.

5. List T, Axelsson S. Management of TMD: evidence from systematic reviews and meta-analyses. J Oral Rehabil. 2010 May;37:430-51. https://doi.org/10.1111/j.1365-2842.2010.02089.x.

6. Wolford LM. Idiopathic condylar resorption of the temporomandibular joint in teenage girls (cheerleaders syndrome). Proc (Bayl Univ Med Cent). 2001;14:246-52. https://www.tandfonline.com/loi/ubmc20.

7. Wolford LM. Concomitant temporomandibular joint and orthognathic surgery. J Oral Maxillofac Surg. 2003;61:1198-204. https://doi.org/10.1053/joms.2002.31220

8. Wolford LM, Reiche-Fischel O, Mehra P. Changes in Temporomandibular Joint Dysfunction After Orthognathic Surgery. J Oral Maxillofac Surg. 2003, 61:655-60. https://doi.org/10.1053/joms.2003.50131

9. Al-Moraissi EA, Wolford LM, Perez D, Laskin DM, Ellis E 3rd. Does Orthognathic Surgery Cause or Cure Temporomandibular Disorders? A Systematic Review and Meta-Analysis. J Oral Maxillofac Surg. 2017,75:1835-47. https://doi.org/10.1016/j.joms.2017.03.029

10. Kim YH. Anterior openbite and its treatment with multiloop edgewise archwire. Angle Orthod. 1987;57:290321. https://doi.org/10.1043/0003-3219(1987)057<0290:AOAITW>2.0.C0;2.

11. Kim YH, Han UK, Lim DD, Serraon ML. Stability of anterior open bite correction with multiloop edgewise archwire therapy: a cephalometric follow-up study. Am J Orthod Dentofacial Orthop. 2000;118:43-54. https://doi.org/10.1067/mod.2000.104830. 
12. Fushima K, Kitamura Y, Mita H, Sato S, Suzuki Y, Kim YH. Significance of the cant of the posterior occlusal plane in class II division 1 malocclusions. Eur J Orthod. 1996;18:27-40. https://doi.org/10.1093/ejo/18.1.27.

13. Huang GJ, Leresche L, Critchlow CW, Martin MD, Drangsholt MT. Risk factors for diagnostic subgroups of painful temporomandibular disorders (TMD). J Dent Res. 2002; 81:284-8. https://doi.org/10.1177/154405910208100412.

14. Leite RA, Rodrigues JF, Sakima MT, Sakima T. Relationship between temporomandibular disorders and orthodontic treatment: a literature review. Dental Press J Orthod. 2013;18:150-57. https://doi.org/10.1590/S2176-94512013000100027.

15. Suvinen TI, Reade PC, Kemppainen P, Kokonen M, Dworkin SF. Review of aetiological concepts of temporomandibular pain disorders: towards a biopsychosocial model for integration of physical disorder factors with psychological and psychosocial illness impact factors. Eur J Pain. 2005;9:613-33. https://doi.org/10.1016/j.ejpain.2005.01.012.

16. Ghurye S, McMillan R. Pain-related temporomandibular disorder: current perspectives and evidence-based management. Dent Update. 2015;42:533-46. https://doi.org/10.12968/denu.2015.42.6.533

17. Michelotti A. An interview with ambrosina michelotti. Dental Press J Orthod. 2018;23:22-29.: https://doi.org/10.1590/2177-6709.23.2.022-029.int.

18. Miller E, Uleryk E, Doria AS. Evidence-based outcomes of studies addressing diagnostic accuracy of MRI of Juvenile Idiopathic Arthritis. Am J Roentgenol. 2009;192:1209-18. https://www.ajronline.org/doi/full/10.2214/AJR.08.2304.

19. Muller L, Kellenberger CJ, Cannizzaro E, Ettlin D, Schraner T, Botl IB et al. Early diagnosis of Temporomandibular joint involvement in Juvenile rheumathoid arthritis: a pilot study comparing clinical examination and ultrasound to magnetic resonance imaging. Reumathology. 2009;48:680-85. https://doi.org/10.1093/rheumatology/kep068.

20. List T, Axelsson S. Management of TMD: evidence from systematic reviews and meta-analyses. J Oral Rehabil. 2010;37:430-51. https://doi.org/10.1111/j.1365-2842.2010.02089.x.

21. Scrivani SJ, Keith DA, Kaban LB. Temporomandibular disorders. N Engl J Med. 2008; 359: 2693-705. DOI: 10.1056/NEJMra0802472

22. Armijo-Olivo S, Pitance L, Singh V, Neto F, Thie N, Michelotti A. Effectiveness of manual therapy and therapeutic exercise for temporomandibular disorders: systematic review and meta-analysis. Phys Ther. 2016; 96:9-25. https://doi.org/10.2522/ptj.20140548

23. A. MICHELOTTI \& G. IODICE. The role of orthodontics in temporomandibular disorders. J Oral Rehabil. 2010;37:411-29. https://doi.org/10.1111/j.1365-2842.2010.02087.x

24. Al-Ani Z, Gray RJ, Davies SJ, Sloan P, Glenny AM. Stabilization splint therapy for the treatment of temporomandibular myofascial pain: a systematic review. J Dent Educ. 2005;69:1242-50. https://doi.org/10.1002/j.0022-0337.2005.69.11.tb04023.x

25. Turp JC, Komine F, Hugger A. Efficacy of stabilization splints for the management of patients with masticatory muscle pain: a qualitative systematic review. Clin Oral Investig. 2004;8:179-95. https://link.springer.com/article/10.1007/s00784-004-0265-4

26. Glaros AG, Owais Z, Lausten L. Reduction in parafunctional activity: a potential mechanism for the effectiveness of splint therapy. J Oral Rehabil. 2007;34:97-104. https://doi.org/10.1111/j.13652842.2006.01660.x 
27. Imai T, Okamoto T, Kaneko T, Umeda K, Yamamoto T, Nakamura S. Long-term follow-up of clinical symptom in TMD patients who underwent occlusal reconstruction by orthodontic treatment. Eur J Orthod. 2000;22:61-7. https://doi.org/10.1093/ejo/22.1.61

28. Zhang C, Wu JY, Deng DL, He BY, Tao Y, Niu YM, Deng MH. Efficacy of splint therapy for the management of temporomandibular disorders: a meta-analysis. Oncotarget. 2016;7:84043-53. DOI:

10.18632/oncotarget.13059

29. Greenlee GM, Huang GJ, Chen SS, Chen J, Koepsell T, Hujoel P. Stability of treatment for anterior open-bite malocclusion: a meta-analysis. Am J Orthod Dentofacial Orthop 2011;139:154-69. https://doi.org/10.1016/j.ajodo.2010.10.019

30. Isaacson RJ, Lindauer SJ. Closing anterior open bites: the extrusion arch. Semin Orthod 2001;7:34-41. https://doi.org/10.1053/sodo.2001.21064

31. Sugawara J et al. Treatment and posttreatment dentoalveolar changes following intrusion of mandibularmolars with application of a skeletal anchorage system (SAS) for open bite correction. Int J Adult Orthod Orthognath Surg. 2002;17:243-53. https://europepmc.org/article/med/12592995

32. Scheffler NR., Proffit WR., and Phillips C. Outcomes and stability in patients with anterior open bite and long anterior face height treated with temporary anchorage devices and a maxillary intrusion splint Am J Orthod Dentofacial Orthop 2014;146:594-602 https://doi.org/10.1016/j.ajodo.2014.07.020

33. Christopher E. Roncone. Complications Encountered in Temporary Orthodontic Anchorage Device Therapy. Semin Orthod. 2011;17:168-79. https://doi.org/10.1053/j.sodo.2011.01.003

\section{Figures}

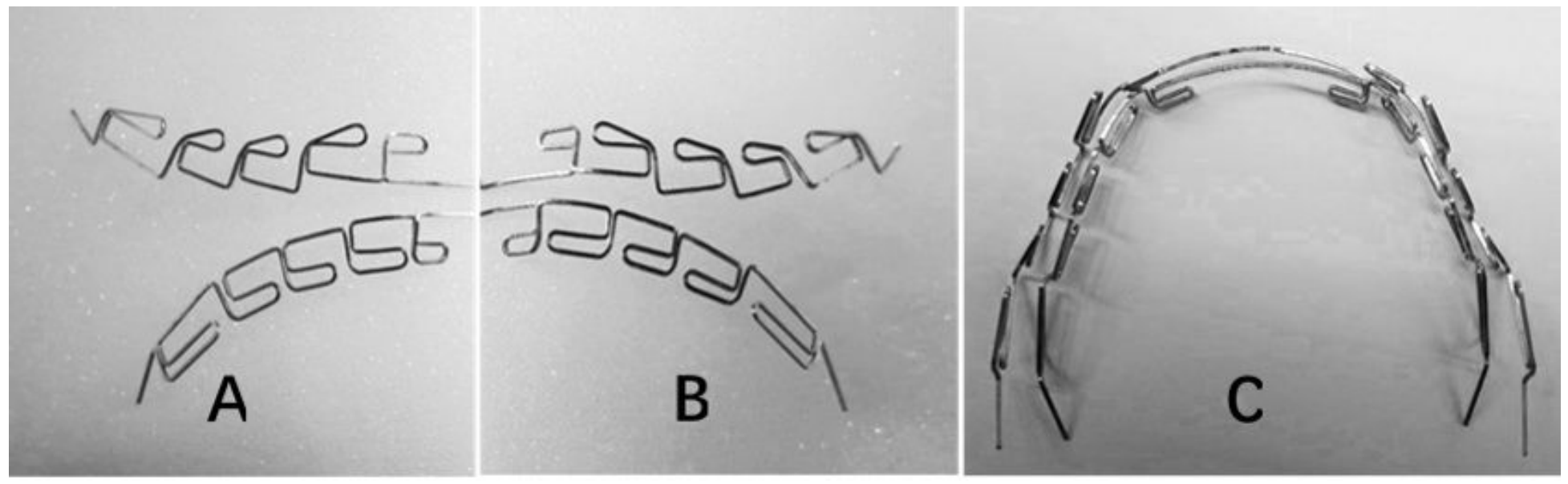

Figure 1

Schematic diagram of the upper and lower MEAW with activation 


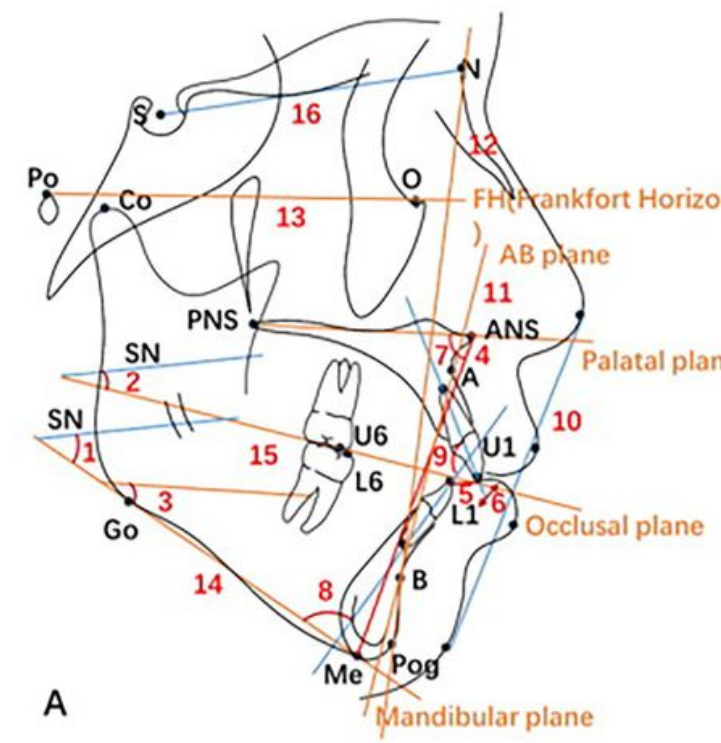

1 Mandibular plane(MP) to $\mathrm{SN}\left({ }^{\circ}\right)$

2 Occlusal plane to $\mathrm{SN}\left({ }^{\circ}\right)$

3 Palato-mandibular plane $\left({ }^{\circ}\right)$

4 lower facial height $(\mathrm{mm})$

5 Overjet $(\mathrm{mm})$

6 Overbite $(\mathrm{mm})$

7 U1 to Palatal plane $\left({ }^{\circ}\right)$

8 IMPA $\left({ }^{\circ}\right)$

9 Interincisor angle $\left({ }^{\circ}\right)$

$10 \mathrm{E}$ line

11 AB Plane

12 Facial plane

13 Frankfort Horizontal Plane

14 Mandibular plane

15 Occlusal plane

$16 \mathrm{SN}$ plane

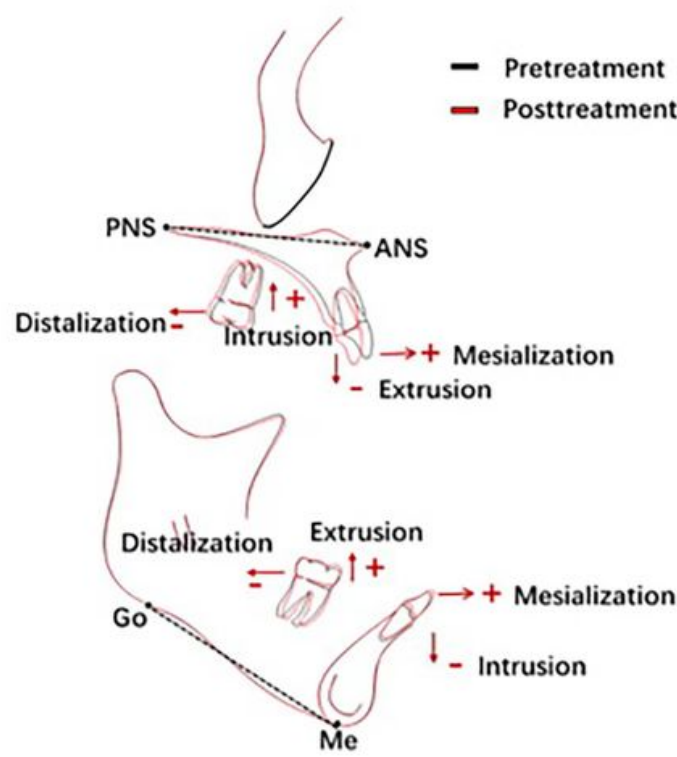

B

C

\section{Figure 2}

A, Cephalometric analysis. B, Maxillary superimposition. The anterior contour of the zygomatic process and palatal plane (ANS-PNS) were used for superimposition. The sign convention for the tooth movement is demonstrated. C, Mandibular superimposition. The anterior contour of the chin, inner cortical structure at the inferior border of the symphysis, and inferior border of the mandible were used for superimposition. The sign convention for tooth movement is demonstrated. 

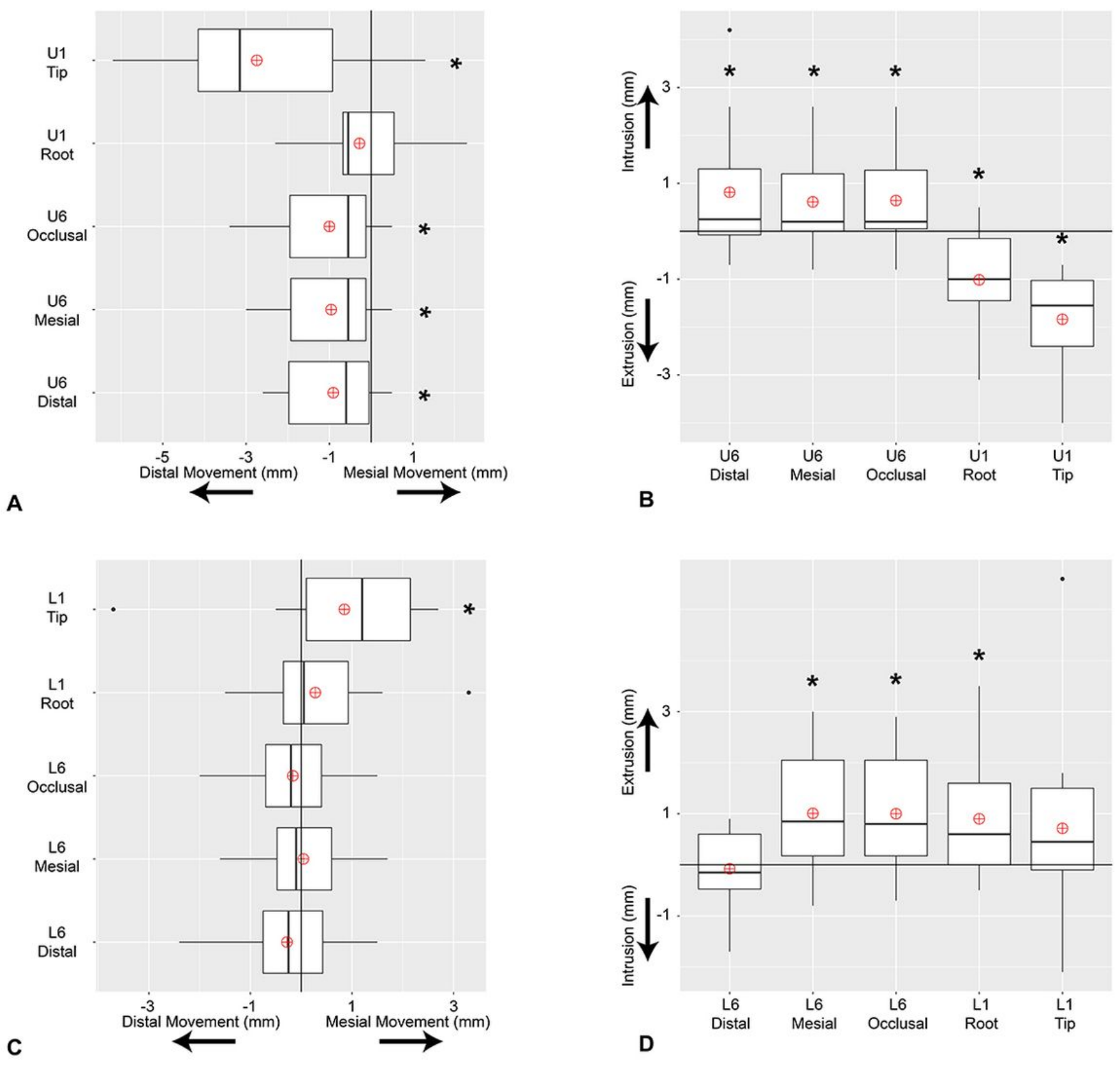

\section{Figure 3}

Amount of tooth movements from maxillary and mandibular regional superimpositions. A, Horizontal displacement of the upper incisor (U1) and molar (U6); B, Vertical displacement of the upper incisor (U1) and molar (U6); C, Horizontal displacement of the lower incisor (L1) and molar (L6); D, Vertical displacement of the lower incisor (L1) and molar (L6); Average amount of movement. 